\title{
Theoretical Study on a Cable-Bracing Inerter System for Seismic Mitigation
}

\author{
Liyu Xie ${ }^{1} \oplus$, Xinlei Ban ${ }^{1}$, Songtao Xue ${ }^{1,2}$, Kohju Ikago ${ }^{3}$, Jianfei Kang ${ }^{1}$ and Hesheng Tang ${ }^{1,4, *}$ \\ 1 Department of Disaster Mitigation for Structures, Tongji University, Shanghai 200092, China; \\ liyuxie@tongji.edu.cn (L.X.); 1610229@tongji.edu.cn (X.B.); xue@tongji.edu.cn (S.X.); \\ 1832540@tongji.edu.cn (J.K.) \\ 2 Department of Architecture, Tohoku Institute of Technology, Sendai 982-8577, Japan \\ 3 International Research Institute of Disaster Science, Tohoku University, Sendai 980-0845, Japan; \\ ikago@irides.tohoku.ac.jp \\ 4 State Key Laboratory of Disaster Reduction in Civil Engineering, Tongji University, Shanghai 200092, China \\ * Correspondence: thstj@tongji.edu.cn; Tel.: +86-21-6598-2390
}

Received: 1 August 2019; Accepted: 24 September 2019; Published: 1 October 2019

\begin{abstract}
In this paper, cables are proposed to connect the inerter and main frame for translation-to-rotation conversion, i.e., the cable-bracing inerter system (CBIS), with a magnified mass and enhanced damping effect. This novel configuration has the benefits of deformation relaxation at the connecting joints, easy installation, and an adaptive layout for nonconsecutive-story deployment. Dynamic motion equations were established for a single degree-of-freedom (SDOF) model equipped with a CBIS. The influence of dimensionless parameters, such as inertance-mass ratio, stiffness ratio and additional damping ratio on vibration mitigation were studied in terms of displacement response and force output. A single objective and multiple objective optimal design method were developed for a CBIS-equipped structure based on a performance-oriented design framework. Finally, the mitigation effect was illustrated and verified by a numerical simulation in a time-domain. The results showed that a CBIS is an effective structural response mitigation device used to mitigate the response of structural systems under earthquake excitation. Using the proposed optimization method, CBIS parameters can be effectively designed to satisfy the target vibration control level.
\end{abstract}

Keywords: passive vibration control; inerter system; cable bracing; parametric study; optimal design

\section{Introduction}

To suppress the structural vibration induced by earthquakes or winds, various vibration control devices have been developed and widely applied [1-3]. Among them, the tuned mass damper (TMD) [4] has the simplest design and a concise vibration control mechanism, which consists of three classical mechanical components, namely mass elements, springs, and dampers. With the addition of a lumped mass in a TMD, the fundamental frequency of the main frame is tuned away from the dominating frequency range of the excitation. Part of the input energy is stored by the lumped mass in the form of kinetic energy, eventually dissipated by the dampers [5,6]. The spring and damper are typical two-terminal elements in the structure, and their output restoring force and damping force depends on the relative displacement and relative velocity between two terminals, respectively. On the other hand, the lumped mass suspended in the TMD [7] is a one-terminal element, and its inertia force exerted on the bearing frame is the product of its absolute acceleration and mass. To control seismic response effectively, the weight of TMDs contributes a significant portion of the entire structure, which demands additional bearing capacity of the main structure. For example, a 660-ton TMD was installed at the top of the Taipei 101 Building in Taiwan, China, whose weight is 0.4 percent of the primary 
structure, taking up nearly two stories of space for installation. The requests for extra space and the weight burden of the TMDs bring practical problems in real applications. Due to space constraints, an active mass damper [8] was installed in a tall TV tower in Nanjing, China to reduce its wind-induced response to replace the original plan of TMDs. An active mass damper has a smaller mass than a TMD, but it requires higher investment and maintenance costs.

To minimize the weight and dimension of a damper, an innovative inerter [9-14] for civil structures has been developed. For the same performance target, the required physical mass of the inerter is much smaller than that of the conventional TMD $[12,15,16]$. For the apparent mass to be much greater than its actual mass, a displacement amplification mechanism must be used, such as the rotation mechanism. The concept of inerter, a two-terminal inertial element, was initially introduced by Smith [17] in the early 2000s. The inertial force produced by an inerter is proportional to the relative acceleration between two terminals, which allows the inerter to utilize the acceleration difference between the adjacent floors for vibration mitigation. Another distinguishing feature is the mass amplification effect of inerters $[9,18]$. The inertance with the apparent mass can be several hundred times greater than its physical mass. An inerter behaves as a tuning element for absorbing vibration energy much like a lumped mass in a TMD does. The topology of an inerter system consists of three basic mechanical elements-the inerter, damping, and spring elements. The damping efficiency in the inerter system can be significantly enhanced by using the rotational amplifier compared to the traditional viscous dampers [17-19].

In civil engineering, a similar concept as inerters had been practiced independently in 1999, Arakaki et al. [20] used the ball screw mechanism to amplify the efficient output force of a viscous damper for suppressing vibrations induced by earthquakes. This was the first application of an inerter-based damper in civil engineering. Since then, various inerter-based devices have been developed, including tuned viscous mass dampers (TVMD) [9,21], tuned mass-damper-inerter systems (TMDI) [12], tuned inerter dampers (TIDs) [22], and so on. These inerter-based devices use rack pinion [22-24], ball screw [9,25], hydraulic [26-28] and electromagnetic [29-31] mechanisms to convert translational movement into rotational movement.

To establish an efficient and practical design method for structures with inerter systems, some theoretical analyses were carried out in the present study. Ikago et al. [9] derived a simple formula for optimal design of TVMD based on the fixed-point theory, which can be used as a design method in practice. Taking the inherent damping ability of a single degree-of-freedom (SDOF) structure into consideration, Pan et al. [32,33] proposed a demand-based optimal design method for a parallel-layout inerter system to satisfy performance demands with minimum control costs. Zhang et al. [34] investigated the impact of the mechanical layout of inerter systems on seismic-response mitigation of liquid-storage tanks, and Chen et al. [35] explored the influence of soil-structure interaction on structures equipped with an inerter system. After these designing measures were undertaken in the engineering applications, some novel inerter-based devices were developed.

Researchers had different approaches to equipping structures with these inerter-based devices. Hwang et al. [36] presented a ball-screw inerter system connected with a toggle brace to magnify the relative displacement between adjacent floors and showed that their system could be utilized effectively in structures even when the drift was small. Makris et al. [23] presented a rack-pinion-flywheel system supported by an infinitely stiff chevron frame and demonstrated that this system was particularly effective in suppressing the peak displacement of structures over long periods of time. Sugimura et al. [31] installed the TVMD system in a building in Tohoku, Japan. This building has seismic response control systems to upgrade the seismic safety of structures and facilities in the Tohoku building. It has traditional viscous dampers supporting the lower floors and the TVMD system supporting the upper floors. The TVMD was fixed between the adjacent floors using a support member with a relevant stiffness like steel. These braces can transmit bending moments, shear, and torque, and are sensitive to displacement at boundaries, which may induce the non-negligible moment and deformation at the TVMD terminals. Ball joints were used to release the deformation which could 
have induced the unwanted internal moment and torque in the brace. Cable bracing is the alternative method to ball joints for connecting inerters, since cables can only bear the axial tension force and release deformation other than the axial direction.

Tension-only cables are an important element in the seismic control systems and are mainly used to transmit control forces and to direct deformation from the main structure to energy dissipating devices. Samuel [37] uses cables to prevent progressive collapse of buildings. Kim et al. [38] proposed a rotational friction damper connected to tension-only braces to enhance the seismic resisting capacity of existing structures. Kurata et al. [39] developed a bracing system consisting of cables and a central energy dissipator. The tension-only cable design can increase the speed of construction by adopting simple connections with rapid installation features.

In this paper, we propose to use a pair of tension-only cables to transfer the story drift to the rotating flywheels, i.e., the cable-bracing inerter system (CBIS). Section 2 will introduce the concept of CBIS and establish the motion governing equation for a CBIS-equipped SDOF system excited by the ground motion. The frequency response functions of displacement and force output are derived for characteristic study. In Section 3, a parametric analysis is conducted to study the effects of CBIS parameters on structural seismic mitigation. In addition, a performance-based multi-objective $\mathrm{H}_{2}$ norm optimum design method is proposed to design the CBIS. Design cases are carried out to illustrate the effects of CBIS and the effectiveness of the proposed design method. Section 4 draws the conclusions. These theoretical studies will lay the foundation for future experimental study.

\section{Theoretical Analysis of a Cable-Bracing Inerter System}

\subsection{CBIS Concept}

Cable bracing is the proposed mechanism of translation-to-rotation conversion for an inerter connected to a structure. Figure 1 shows an SDOF structure with a CBIS, which consists of a pair of bracing cables, a pair of conductor plates (flywheels), and a shaft. A pair of cables is pre-tensioned connecting the structural frame and the shaft diagonally. Both ends of the shaft are supported by a pair of shaft bearings mounted on the side plates fixed on the ground floor, making sure that only the shaft rotates. When inter-story drift occurs in structures, one of the cables will shorten and drive the shaft into rotation. The low-speed translational movement of the structure can be converted into a high-speed rotational motion of the conductor plates by cable bracing.

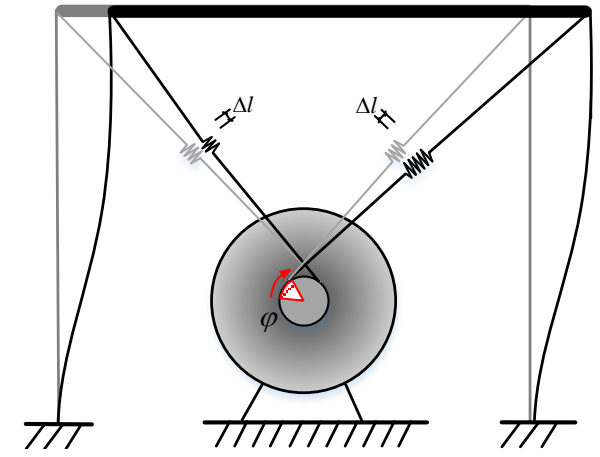

(a)

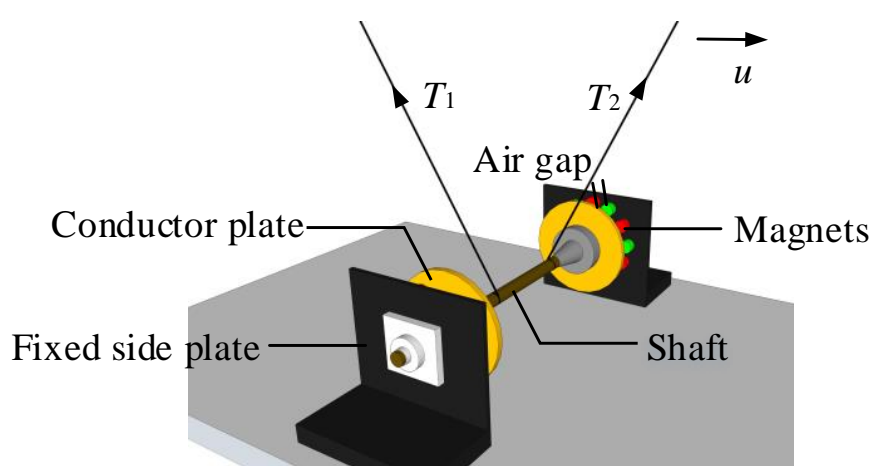

(b)

Figure 1. A single-degree-of-freedom (SDOF) structure with a CBIS: (a) structure with a CBIS and (b) detail of a CBIS. Note that the conductor plates serve as flywheels.

Conductor plates are fixed on the shaft and rotate together; meanwhile, several magnets with alternating magnetic polarization are allocated on the fixed side plate to generate the electromagnetic field. The rotational conductor plates and shaft function as an inerter. The fixed side plate and conductor plate form one eddy current damper when the rotation conductor plate is cutting through the electromagnetic field, thereby dissipating the vibration energy in the form of heat. As a result, 
the novel cable-bracing inerter system presented herein can obtain its inertance and enhance the energy dissipation capacity via the additional damping provided by the eddy current damping. Compared to the classic ball-screw mechanism of an inerter, CBIS is cost-effective and very simple.

\subsection{Inerter Element}

An inerter element is a two-terminal element. The output force is proportional to the relative acceleration between two terminals and can be expressed as:

$$
p=m_{\mathrm{d}}\left(a_{2}-a_{1}\right)
$$

where $p$ is the output force of the inerter element, and $m_{\mathrm{d}}$ is the inertance; moreover, $a_{1}$ and $a_{2}$ are the accelerations at the two terminals of the inerter element, as depicted in Figure 2.

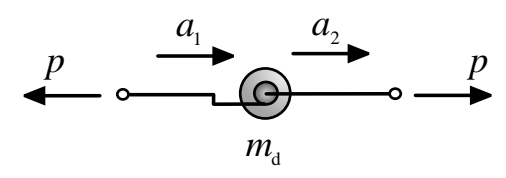

Figure 2. Mechanical model of an inerter element.

\subsection{Layout of SDOF System with CBIS}

The mechanical system of a CBIS consists of an additional damping element, an inerter element and a spring element. The damping element is set in parallel with the inerter element. The spring element is then connected with the paralleled inerter and damping element in a series. Figure 3 shows the layout and mechanical model of an SDOF structure equipped with a CBIS when the structure is deformed in a horizontal direction.

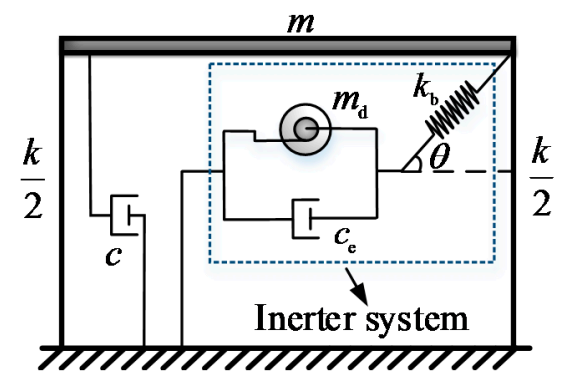

Figure 3. Layout of an SDOF system with a CBIS.

In Figure 3, $m, c$, and $k$ are the mass, damping coefficient, and stiffness of the SDOF system, the primary structure, respectively. $\theta$ is the inclined angle of the diagonal cable; $m_{\mathrm{d}}$ is the inertance of the CBIS; $c_{\mathrm{e}}=c_{\mathrm{d}} \cos ^{2} \theta$ is the equivalent damping coefficient considering the inclined angle of the cables, where $c_{\mathrm{d}}$ is the damping coefficient of the damping element, and $k_{\mathrm{b}}$ is the stiffness of the supporting spring element. The output force of this inerter system is the resultant force of the inerter element and the eddy current damping element.

\subsection{Motion Governing Equation of SDOF System with CBIS}

When the structure is in a balanced state, the prestressed tension forces in both cables are $T_{0}$. If the structure starts to leave the balance position by moving to the right as illustrated in Figure 4, the diagonal cable on the right side drives the inerter to rotate clockwise. At this time, the force increment in the right cable is $\Delta T$, and the force becomes $T_{2}\left(T_{2}=T_{0}+\Delta T\right)$. The tension in the left cable decreases $\Delta T$ and becomes $T_{1}\left(T_{1}=T_{0}-\Delta T\right)$. 


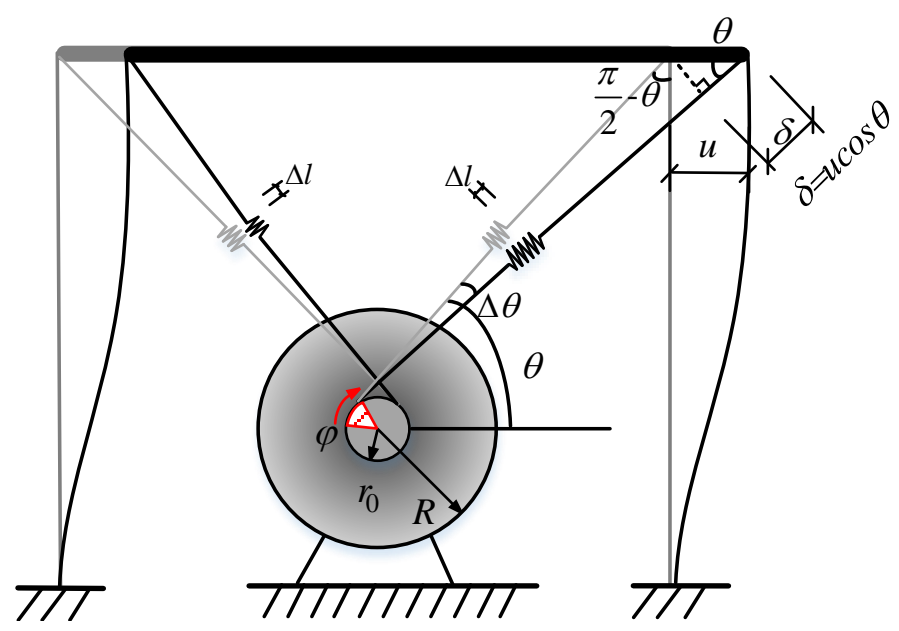

Figure 4. Transmission mechanism of cable-bracing inerter system.

When the structure has a positive deformation, it moves to the right with a relative displacement $u(t)$, and the shaft and the conductor plates rotate correspondingly. We assume there is no relative slippage between the cable and the shaft. Considering the axial stiffness of the one-sided cable $k_{b}{ }^{0}$, the forces in the right cable $T_{2}$ and the left cable $T_{1}$ are as follows:

$$
\begin{aligned}
& T_{2}=T_{0}+k_{\mathrm{b}}{ }^{0}\left(u(t) \cos \theta-\varphi(t) r_{0}\right) \\
& T_{1}=T_{0}-k_{\mathrm{b}}{ }^{0}\left(u(t) \cos \theta-\varphi(t) r_{0}\right),
\end{aligned}
$$

where the rotational angle of the conductor plate is $\varphi(t)$. As shown in Figure 5, when the conductor plates rotate, the cable moves in its own axial direction. Thus, the angle difference $\Delta \theta$ from its balance position is trivial and can be ignored. $u(t) \cos \theta-\varphi(t) r_{0}$ is the axial elongation of the cable. During the operation of a CBIS, the tension force difference between two cables drives the shaft to rotate and is given as:

$$
T_{2}-T_{1}=2 k_{\mathrm{b}}^{0}\left(u(t) \cos \theta-\varphi(t) r_{0}\right) .
$$

The eddy currents cause a damping force that is proportional to the velocity of the conductive metal, which makes the eddy currents function like a viscous damper. According to the force equilibrium conditions, compatibility condition, and the layout of the system (as shown in Figure 3), the motion equation for this SDOF structure with a CBIS under earthquake excitations can be written as:

$$
m \ddot{u}(t)+c \dot{u}(t)+k u(t)+k_{\mathrm{b}}\left(u(t) \cos \theta-\varphi(t) r_{0}\right) \cos \theta=-m a_{g}(t),
$$

where $u(t)$ is the relative displacement of the SDOF system, and the dots represent the derivative with respect to time $t . a_{\mathrm{g}}(t)$ is the acceleration of the ground motion, $k_{\mathrm{b}}$ is the equivalent stiffness of two cables, and it is used to replace $2 k_{b}{ }^{0}$ in Equation (3). The motion equation for the CBIS is written as:

$$
J \ddot{\varphi}(t)+c_{\mathrm{d}} \dot{\varphi}(t) r_{0}^{2}=k_{\mathrm{b}}\left(u(t) \cos \theta-\varphi(t) r_{0}\right) r_{0},
$$

where $J$ is the moment of inertia for the inerter, and $r_{0}$ is the radius of the shaft. The conductor plate serves as a flywheel whose moment of inertia can be calculated as:

$$
J=m_{\mathrm{I}} R^{2} / 2,
$$

where $m_{\mathrm{I}}$ is the physical mass of two conductor plates and the shaft, and $R$ is the radius of gyration. 
The governing motion equation of an SDOF structure can be described as:

$$
\left[\begin{array}{cc}
m & 0 \\
0 & J
\end{array}\right]\left\{\begin{array}{c}
\ddot{u} \\
\ddot{\varphi}
\end{array}\right\}+\left[\begin{array}{cc}
c & 0 \\
0 & c_{\mathrm{d}} r_{0}^{2}
\end{array}\right]\left\{\begin{array}{c}
\dot{u} \\
\dot{\varphi}
\end{array}\right\}+\left[\begin{array}{cc}
k+k_{\mathrm{b}} \cos ^{2} \theta & -k_{\mathrm{b}} r_{0} \cos \theta \\
-k_{\mathrm{b}} r_{0} \cos \theta & k_{\mathrm{b}} r_{0}^{2}
\end{array}\right]\left\{\begin{array}{c}
u \\
\varphi
\end{array}\right\}=\left[\begin{array}{c}
-m a_{g} \\
0
\end{array}\right] .
$$

Therefore, Equation (7) can be expressed in matrix form as:

\section{$\mathrm{MX}+\mathrm{CX}+\mathrm{KX}=\mathrm{F}$}

where $\mathbf{M}, \mathbf{C}, \mathbf{K}$ and $\mathbf{F}$ respectively represent the mass matrix, damping matrix, stiffness matrix and external excitation vector of the SDOF system with a CBIS. Equation (8) is converted into the state space form:

$$
\mathbf{A} \bar{X}+\mathbf{B} \bar{X}=\left\{\begin{array}{l}
F \\
0
\end{array}\right\}
$$

where $\mathbf{0}=\{\mathbf{0}, \mathbf{0}\}^{T}, \mathbf{A}, \mathbf{B}, \overline{\mathbf{X}}$ and $\overline{\mathbf{X}}$ are determined as:

$$
\mathbf{A}=\left[\begin{array}{cccc}
c & 0 & m & 0 \\
0 & c_{\mathrm{d}} r_{0}^{2} & 0 & J \\
m & 0 & 0 & 0 \\
0 & J & 0 & 0
\end{array}\right], \mathbf{B}=\left[\begin{array}{cccc}
k+k_{\mathrm{b}} \cos ^{2} \theta & -k_{\mathrm{b}} r_{0} \cos \theta & 0 & 0 \\
-k_{\mathrm{b}} r_{0} \cos \theta & k_{\mathrm{b}} r_{0}^{2} & 0 & 0 \\
0 & 0 & -m & 0 \\
0 & 0 & 0 & -J
\end{array}\right], \overline{\mathbf{x}}=\left\{\begin{array}{c}
u \\
\varphi \\
\dot{u} \\
\dot{\varphi}
\end{array}\right\}, \overline{\mathbf{X}}=\left\{\begin{array}{c}
\dot{u} \\
\dot{\varphi} \\
\ddot{u} \\
\ddot{\varphi}
\end{array}\right\}
$$

Assume that the solution of Equation (9) has the form of:

$$
\overline{\mathbf{X}}=\boldsymbol{\psi} \mathbf{e}^{\lambda t}, \overline{\mathbf{X}}=\psi \lambda \mathbf{e}^{\lambda t}
$$

where $\psi$ is the eigenvector, substituting $\psi=\left[\psi_{1} \psi_{2}\right]^{\mathrm{T}}$ into Equation (9), whereby we obtain:

$$
(\mathbf{A} \lambda+\mathbf{B})\left\{\begin{array}{c}
\psi \\
\psi \lambda
\end{array}\right\}=0 .
$$

The characteristic equation can be expressed as:

$$
\operatorname{det}|\mathbf{A} \lambda+\mathbf{B}|=0 .
$$

The $j$ th pair of eigenvalues are $\lambda_{2 j-1}$ and $\lambda_{2 j}$, and the $j$ th fundamental angular frequency $\omega_{j}$ can be obtained as:

$$
\omega_{j}=\left|\lambda_{2 j-1}\right|=\left|\lambda_{2 j}\right|
$$

\subsection{Frequency Response Function}

In this section, the frequency response function of an SDOF structure with a CBIS under seismic excitation is obtained. To normalize the dynamic equation, the parameters can be defined as:

$$
\begin{gathered}
\omega_{\mathrm{s}}=\sqrt{\frac{k}{m}}, \\
\zeta=c / 2 m \omega_{\mathrm{s}} \\
\xi=c_{\mathrm{d}} / 2 m \omega_{\mathrm{s}}
\end{gathered}
$$


where $\omega_{\mathrm{s}}$ and $\zeta$ are the circular frequency and the inherent damping ratio of the original SDOF structure, respectively. $\xi$ is the additional damping ratio provided by the CBIS. Through dimensionless processing, the following parameters can be defined for designing CBIS:

$$
\begin{gathered}
\mu=m_{\mathrm{d}} / m, \\
\kappa=k_{\mathrm{b}} \cos ^{2} \theta / k,
\end{gathered}
$$

where $\mu$ is inertance-mass ratio, a ratio of the inertance of CBIS to the mass of primary system. $\kappa$ is the ratio of supporting spring stiffness in the horizontal direction to the primary stiffness $k$. Substituting the parameters in Equations (15)-(19) into Equation (9), the Laplace transformation of Equation (7) can be written as:

$$
\left[\begin{array}{c}
s U \\
s^{2} U \\
s \Phi \\
s^{2} \Phi
\end{array}\right]=\left[\begin{array}{cccc}
0 & 1 & 0 & 0 \\
-\omega_{\mathrm{s}}^{2}-\kappa \omega_{\mathrm{s}}^{2} & -2 \zeta \omega_{\mathrm{s}} & \kappa \omega_{\mathrm{s}}^{2} r_{0} / \cos \theta & 0 \\
0 & 0 & 0 & 1 \\
\kappa \omega_{\mathrm{s}}{ }^{2} m r_{0} / J \cos \theta & 0 & -\kappa \omega_{\mathrm{s}}^{2} m r_{0}^{2} / J \cos ^{2} \theta & -2 \xi \omega_{\mathrm{s}} r_{0}{ }^{2} m / J
\end{array}\right]\left[\begin{array}{c}
U \\
s U \\
\Phi \\
s \Phi
\end{array}\right]-\left[\begin{array}{c}
0 \\
1 \\
0 \\
0
\end{array}\right] A_{g}(s)
$$

where $s=i \omega$, and $A_{\mathrm{g}}(s)$ is the Laplace transformation of $a_{\mathrm{g}}(t) . \dot{U}, \dot{U}, \Phi$ and $\dot{\Phi}$ are the Laplace transformations of $u, \dot{u}, \varphi$ and $\dot{\varphi}$, respectively, and they can be solved from Equation (8):

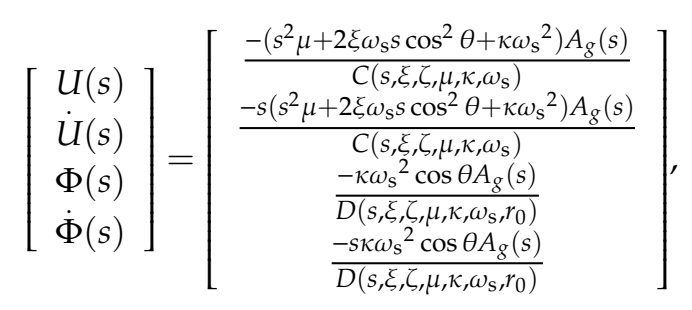

where

$$
\begin{aligned}
& C\left(s, \xi, \zeta, \mu, \kappa, \omega_{\mathrm{s}}\right)=s^{4} \mu+2 s^{3}\left(\xi \cos ^{2} \theta+\zeta \mu\right) \omega_{\mathrm{s}}+s^{2}\left(\kappa+4 \xi \zeta \cos ^{2} \theta+\mu+\kappa \mu\right) \omega_{\mathrm{s}}^{2} \\
& +2 s\left(\zeta \kappa+\xi \cos ^{2} \theta+\kappa \xi \cos ^{2} \theta\right) \omega_{\mathrm{s}}^{3}+\kappa \omega_{\mathrm{s}}{ }^{4} \\
& D\left(s, \xi, \zeta, \mu, \kappa, \omega_{\mathrm{s}}, r_{0}\right)=s^{4} \mu r_{0}+2 s^{3}\left(r_{0} \xi \cos ^{2} \theta+r_{0} \zeta \mu\right) \omega_{\mathrm{s}}+s^{2}\left(\kappa \mu r_{0}+4 \xi \zeta \cos ^{2} \theta r_{0}\right. \\
& \left.+\mu r_{0}+\kappa r_{0}\right) \omega_{\mathrm{s}}{ }^{2}+2 s\left(\xi \kappa r_{0}+\zeta \kappa r_{0}+\xi \cos ^{2} \theta r_{0}\right) \omega_{\mathrm{s}}{ }^{3}+\kappa r_{0} \omega_{\mathrm{s}}{ }^{4} .
\end{aligned}
$$

The frequency-domain transfer function between $u(t)$ and input excitations can be easily obtained as:

$$
H_{U}(s)=\frac{U(s)}{A_{g}(s)}=\frac{-\left(s^{2} \mu+2 \xi \omega_{\mathrm{s}} s \cos ^{2} \theta+\kappa \omega_{\mathrm{s}}^{2}\right)}{C\left(s, \xi, \zeta, \mu, \kappa, \omega_{\mathrm{s}}\right)} .
$$

The normalized force of the CBIS is defined as $F(t)=k_{\mathrm{b}}\left(u(t) \cos \theta-\varphi(t) r_{0}\right) / m$, which is provided by the inertial mass element and the eddy current damping element. The frequency-domain transfer function between $F(t)$ and the input excitation is given as:

$$
H_{F}(s)=\frac{F(s)}{A_{g}(s)}=\frac{-\left(2 \kappa \xi \omega_{\mathrm{s}}^{3} s \cos ^{2} \theta+\kappa \omega_{\mathrm{s}}^{2} \mu s^{2}\right)}{A\left(s, \xi, \zeta, \mu, \kappa, \omega_{\mathrm{s}}\right) \cos \theta}
$$

\section{Parametric Study}

In this section, parametric analyses will be performed to investigate the effects of CBIS parameters on structural seismic mitigation. The mitigation effect is represented in terms of the moduli of displacement and force frequency response function at the resonant frequency. Three arguments, namely the inertance-mass ratio $\mu$, stiffness ratio $\kappa$, and additional damping ratio $\xi$, vary to study the control effect of a CBIS damper. The domain of these arguments is determined mathematically without considering practical aspects. 


\subsection{Analysis Index}

The response of a structure at the resonant frequency is much greater than that at another frequency, so the peak value of the system's responses deserves much attention. To find out the maximum displacement response of the structure, the displacement amplification factor is referred to as the $H_{\infty}$ norm and can be defined as:

$$
H_{\infty}=\max \left\{\left|H_{U}(i \beta)\right| \omega_{\mathrm{s}}^{2}\right\},
$$

where $\beta=\omega / \omega_{\mathrm{s}}$, and it can be interpreted as the normalized frequency. This index is independent of the natural circular frequency $\omega_{\mathrm{s}}$ of the original structure, and can be considered as a function, depending on the original structure's inherent damping ratio $\zeta$ and the CBIS parameters, $\mu, \xi$, and $\kappa$. Henceforth, the intention of vibration control is to minimize the displacement amplification factor in terms of the $H_{\infty}$ norm for a set of optimal parameters of the CBIS.

\subsection{Parametric Analysis Results}

Based on the analysis indexes mentioned above, a series of numerical cases were considered. In these cases, the inherent damping ratio for the main frame $\zeta=0.02$ was assumed. Three inertance-mass ratios, namely, $\mu=0.01,0.1$ and 1.0, were used to study the vibration control effects by continuously varying $\kappa$ and $\xi$ within specified ranges. To describe the controlling index of the SDOF with a CBIS, contour plots were illustrated with $\xi$ on the $x$-axis, $\kappa$ on the $y$-axis, and $\max \left\{\left|H_{U}(i \beta)\right| \omega_{\mathrm{s}}^{2}\right\}$ as the height, as shown in Figure 5.

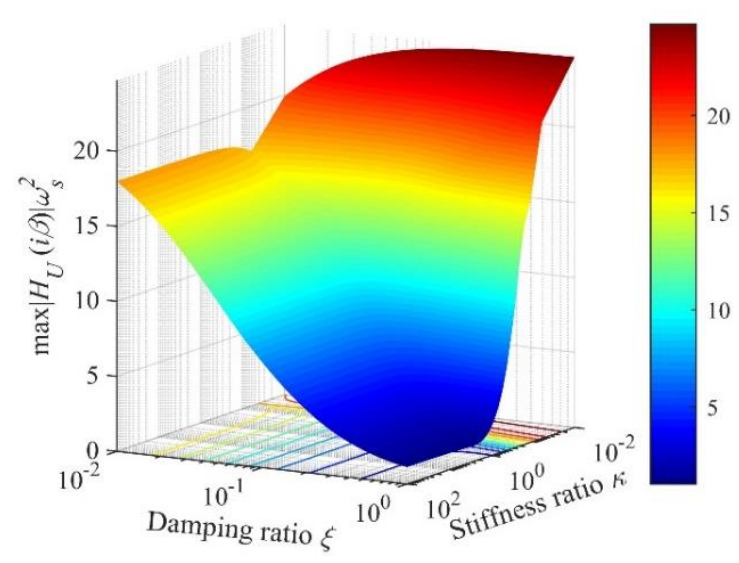

(a) $\mu=0.01$

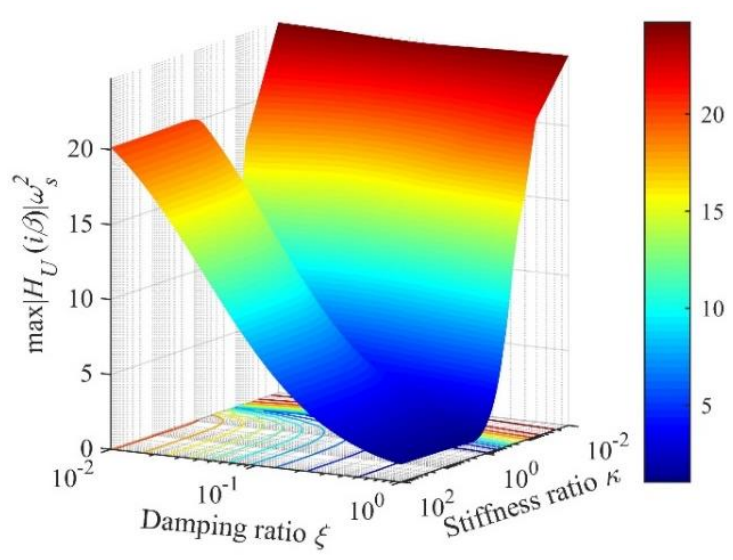

(b) $\mu=0.1$

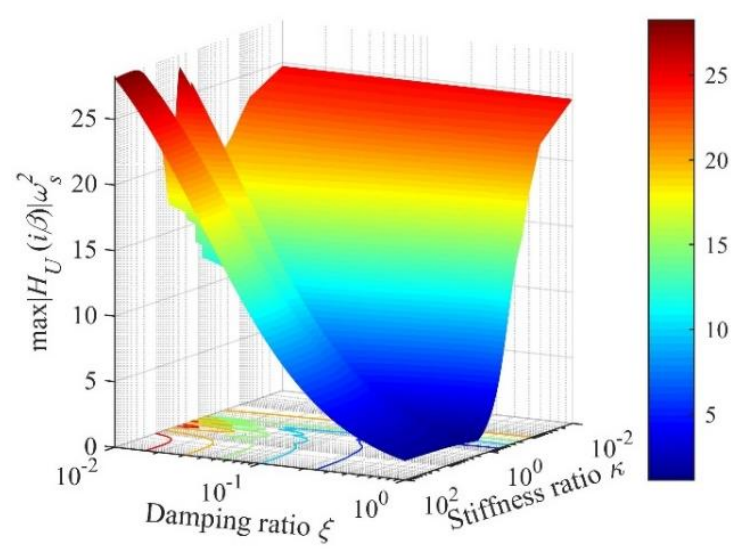

(c) $\mu=1$

Figure 5. Displacement amplification factor of a CBIS-equipped SDOF structure with changes in $\kappa \in[0.01,100]$ and $\xi \in[0.01,1]$. 
The displacement amplification factor of any point in the $\kappa-\xi$ space is determined by the frequency response function of Equation (25). The magnitude is represented by the color intensity. The lowest displacement amplification factor is in the corner of the $\kappa-\xi$ space, where the two parameters reach their upper bounds. As shown in Figure $5 \mathrm{a}-\mathrm{c}$, the desirable solution of the dynamic response ratio is determined by the feasible upper bounds of the CBIS parameters in the given ranges. Mathematically, the optimal configuration for vibration control requires the stiffness ratio and additional damping to be as large as possible. However, both are impossible to realize in actual engineering. It is necessary to introduce appropriate boundary conditions or constraints for practical optimization processes.

When the additional damping ratios are fixed, for example $\xi=0.05,0.1$, closed contour lines can be obtained (as shown in Figure 6). A very low point implies that the parameter set for optimal control can always be found in the inner part of every contour. This means that optimal solutions lie within the inner part of the parametric space. When the stiffness ratio closes to 1 , and the inertance-mass ratio closes to 0.1 , the displacement response reaches its lowest point. In this process, the optimal additional damping ratio $\xi$ remains unknown. Therefore, the selection of a rational parameter set for the design of CBIS based on only the displacement response is difficult. However, for many situations, the optimization will involve a recursive process in which the optimal configuration keeps updating with a prescribed additional damping ratio $\xi$ until the mitigation effect satisfies the objective.

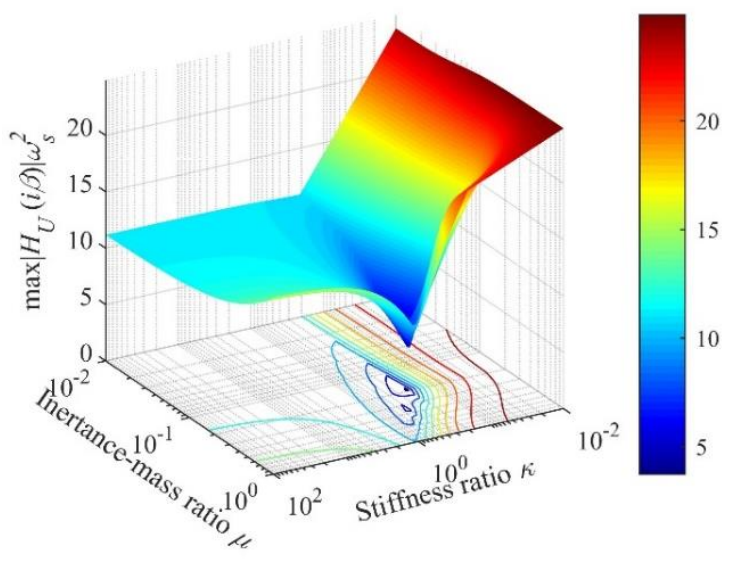

(a) $\xi=0.05$

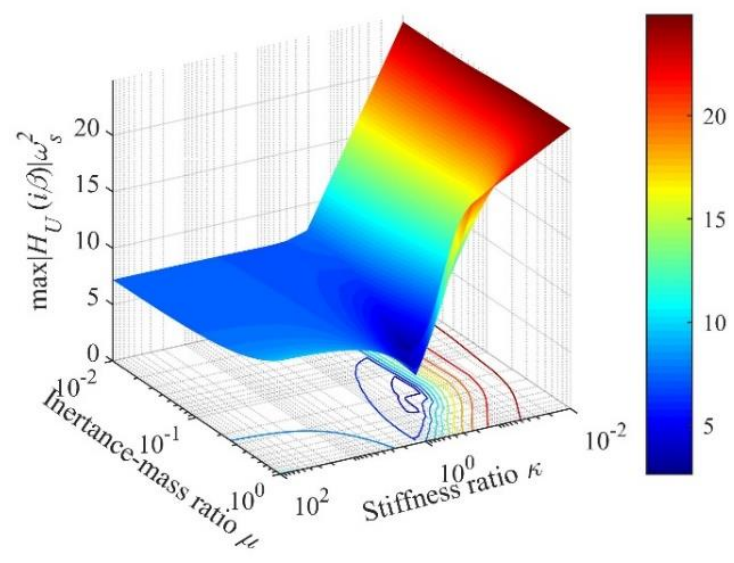

(b) $\xi=0.1$

Figure 6. Displacement amplification factor of a CBIS-equipped SDOF structure with changes in $\kappa \in[0.01,100]$ and $\mu \in[0.01,1]$.

In Figure 6, the displacement responses reach their optimal points when the stiffness ratio closes to 1 , and the inertance-mass ratio closes to $[0.1,0.5]$, where the force response of the inerter system is relatively large (as shown in Figure 7). In the optimization design, it is unreasonable to consider only the structural displacement, or the force response provided by the inerter element. Therefore, both the displacement responses and the inerter element's force should be considered in the design of CBIS. The demand-oriented multi-objective optimum design method will be introduced in the next section, and the control force response of the CBIS will be brought into the optimization process as the secondary objective. 


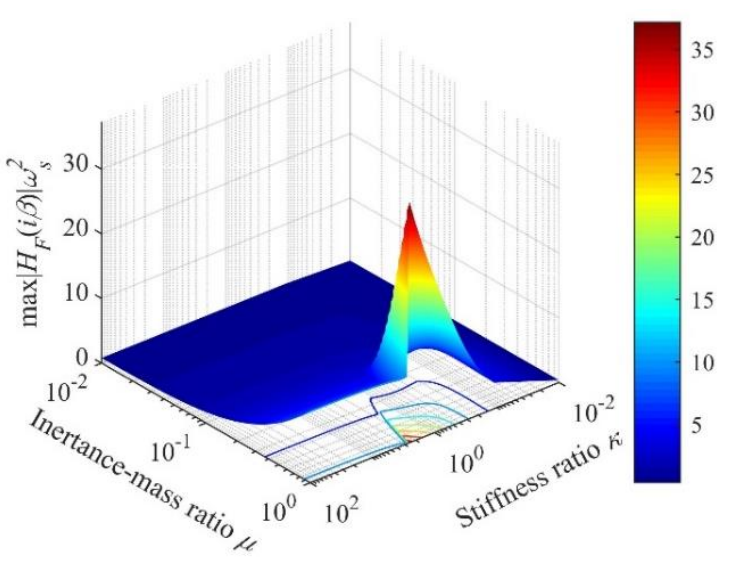

(a) $\xi=0.05$

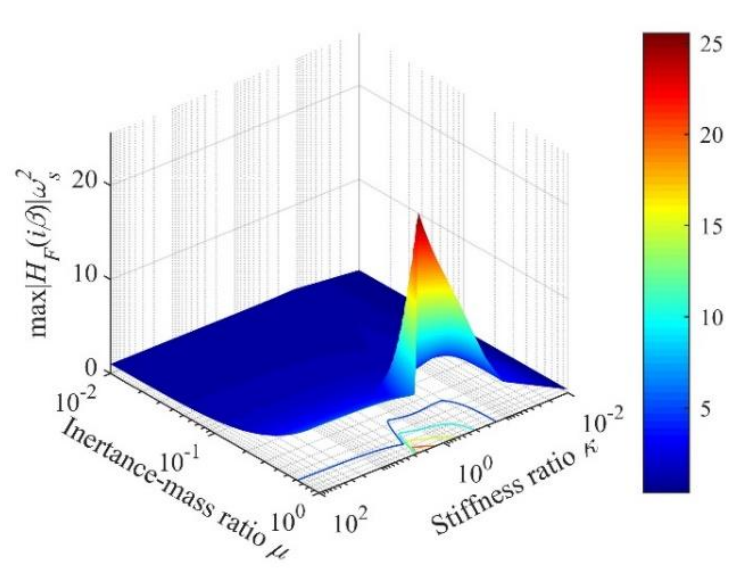

(b) $\xi=0.1$

Figure 7. Force amplification factor of the inerter system.

\subsection{Multi-Objective $\mathrm{H}_{2}$ Norm Optimum Design}

Three unknown parameters can be designed optimally according to performance demands. An optimization method is proposed to achieve the desired performance levels (structure's displacement $u$ ) with low control output force (CBIS's force $f_{\mathrm{d}}$ ). In other words, the goal is to suppress the displacement of the structure as thoroughly as possible while minimizing the output force of the inerter system. Therefore, both the displacement response and the CBIS force should be considered in the design of this inerter system. Two dimensionless response variation ratios [32] are defined as: namely, the displacement reduction ratio, $\gamma_{U}$ and the force ratio, $\gamma_{F_{\mathrm{d}}}$, which can be expressed as:

$$
\begin{aligned}
& \gamma_{U}(\zeta, \mu, \xi, \kappa)=\frac{\sigma_{U}}{\sigma_{U_{0}}}=\frac{\sqrt{\int_{-\infty}^{\infty}\left|H_{U}(i \omega)\right|^{2} d \omega}}{\sqrt{\int_{-\infty}^{\infty}\left|H_{U_{0}}(i \omega)\right|^{2} d \omega}}, \\
& \gamma_{F_{\mathrm{d}}}(\zeta, \mu, \xi, \kappa)=\frac{\sigma_{F_{\mathrm{d}}}}{\sigma_{F_{\mathrm{d} 0}}}=\frac{\sqrt{\int_{-\infty}^{\infty}\left|H_{F_{\mathrm{d}}}(i \omega)\right|^{2} d \omega}}{\sqrt{\int_{-\infty}^{\infty}\left|H_{F_{\mathrm{d} 0}}(i \omega)\right|^{2} d \omega}} .
\end{aligned}
$$

In these expressions, $\gamma_{U}$ is the ratio of the CBIS-equipped structure's displacement, compared with the primary structure, and $\gamma_{F_{\mathrm{d}}}$ is the dimensionless force of the CBIS. $\sigma_{U}$ is the root mean square (RMS) of the output displacement response of the structure equipped with CBIS, and $\sigma_{U_{0}}$ is the displacement response of the primary structure. $\sigma_{F_{\mathrm{d}}}$ is the force of the RMS response of the structure equipped with CBIS, and $\sigma_{F_{\mathrm{d} 0}}$ is the force RMS response of the original structure. $\left|H_{U_{0}}(i \omega)\right|$ and $\left|H_{F_{\mathrm{d} 0}}(i \omega)\right|$ are the displacement and damping force (caused by the inherent damping) transfer function moduli of the original structure, respectively. The optimization of CBIS can be expressed mathematically as:

$$
\begin{gathered}
\underset{\mu, \xi, \kappa}{\operatorname{minimize}}\left[\gamma_{U}(\mu, \xi, \kappa), \gamma_{F_{\mathrm{d}}}(\mu, \xi, \kappa)\right], \\
\text { subject to }\left\{\begin{array}{l}
\mu_{\min } \leq \mu \leq \mu_{\max } \\
\xi_{\min } \leq \xi \leq \xi_{\max } \\
\kappa_{\min } \leq \kappa \leq \kappa_{\max }
\end{array}\right.
\end{gathered}
$$

where $\mu, \xi$ and $\kappa$ are decision variables, and $\mu_{\min }, \xi_{\min }$, and $\kappa_{\min }$ are the lower bounds of $\mu, \xi$ and $\kappa$, while $\mu_{\max }, \xi_{\max }$, and $\kappa_{\max }$ are the upper bounds, respectively. Multi-objective optimization (MOO) is used to find the boundary of the feasible criterion space where all optimal points lie: namely, Pareto Front (shown in Figure 8). On this boundary, there are many points. Based on the demanding 
performance, a reasonable optimization parameter for $\gamma_{U} \leq 40 \%$ and the corresponding $\gamma_{F_{\mathrm{d}}}$ can be found. Furthermore, a set of parameters was selected for time domain analysis, as shown in Table 1.

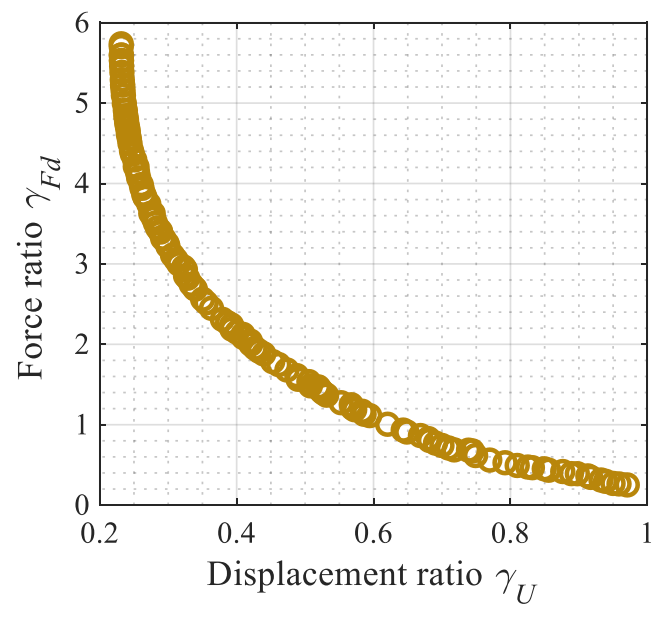

Figure 8. Pareto optimal front.

Table 1. Results of performance-based design optimization.

\begin{tabular}{cccccc}
\hline \multicolumn{2}{c}{ Optimized Design Parameters } & $\begin{array}{c}\text { Displacement } \\
\text { Response Ratio }\end{array}$ & Force Ratio & $\begin{array}{c}\text { Energy Dissipation } \\
\text { Efficiency }\end{array}$ \\
\hline $\begin{array}{c}\text { Inertance-mass ratio } \\
0.0198\end{array}$ & Damping ratio & Stiffness ratio & $\gamma_{U}$ & $\gamma_{F_{\mathrm{d}}}$ & $\psi$ \\
\hline
\end{tabular}

One of the advantages of a CBIS over a viscous element is that it can enhance the energy dissipation efficiency. The energy dissipation enhancement mechanism is described by the factor $\psi$ [32] (shown in Table 1), which equals the ratio of the response mitigation of an SDOF structure with CBIS to that of an SDOF structure with a viscous element having the same additional damping coefficient as the CBIS, that is:

$$
\psi=\frac{\sigma_{U_{0}}(\zeta)-\sigma_{U}(\mu, \xi, \kappa)}{\sigma_{U_{0}}(\zeta)-\sigma_{U_{0}}(\zeta+\xi)}
$$

The degree of the energy dissipation enhancement of the CBIS can be adjusted by adding the following supplementary constraint condition to the optimization problem by:

$$
\psi \geq \psi_{0}
$$

where $\psi_{0}$ is a constant during and the recommended range $1<\psi_{0} \leq 2$, according to the many numerical case studies [32]. Here, $\psi$ is 8.7517 , which means that the inerter element has fully played its role, and, in the case of the same additional damping ratio, the energy dissipation efficiency of CBIS is 8.7517 times that of a purely viscous element. To illustrate the effects of CBIS on the seismic performance in the time domain, dynamic time-history analyses were conducted to further verify the design results under harmonic excitation and seismic excitations. Four seismic waves are used as external excitations-the El Centro record (1940, NS), the ground motion recorded at Tohoku University during the 2011 Tohoku earthquake $\left(\mathrm{M}=9.0, \mathrm{PGA}=3.33 \mathrm{~m} / \mathrm{s}^{2}\right)$, Kobe record (1995) and Chi-chi record (1999). The Tohoku wave occurred on 11 March 2011 and was part of the most powerful known earthquake in Japan. For the SDOF structure, the inherent damping ratio is $\zeta=0.02$. The natural period on the rigid base is $1.00 \mathrm{~s}$. 


\subsubsection{Harmonic Excitation}

Using the performance-based optimization results in Table 1, the controlled and uncontrolled responses of the structure are compared under harmonic excitations. The natural frequency of the structure is $1 \mathrm{~Hz}$ and the frequency range of harmonic excitations is $0-3 \mathrm{~Hz}$. Figure 9 shows displacement amplification factors of the uncontrolled and a CBIS-equipped SDOF structure. The peak value reduction effect is $71.75 \%$. The response of a structure at the resonant frequency is significantly reduced by the CBIS.

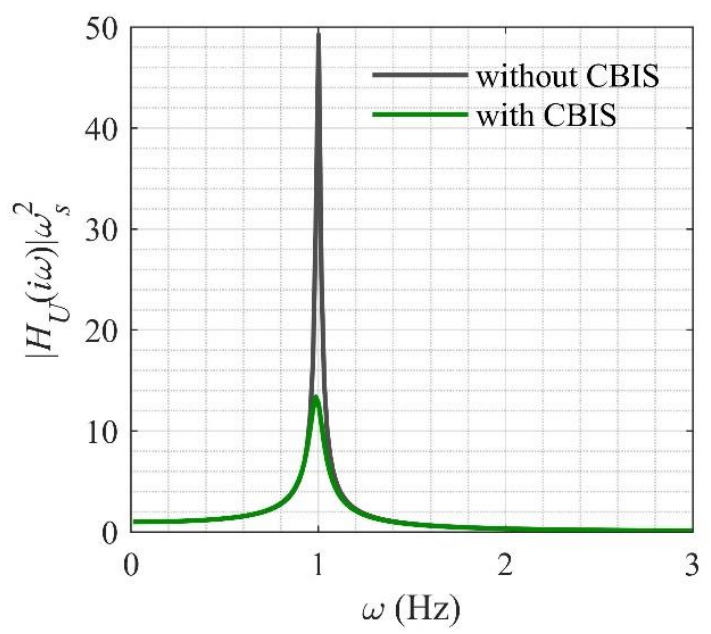

Figure 9. Displacement amplification factors.

\subsubsection{Earthquake Excitation}

Figures 10 and 11 show the SDOF structures' acceleration and displacement responses. The peak value and RMS value of the displacement and acceleration responses were chosen to evaluate the vibration mitigation performance of CBIS. These values are both important controlling indices in structural vibration control. The peak value reflects the dynamic response at a certain instant, whereas the RMS value indicates the vibration energy and reflects the responses over an entire period.

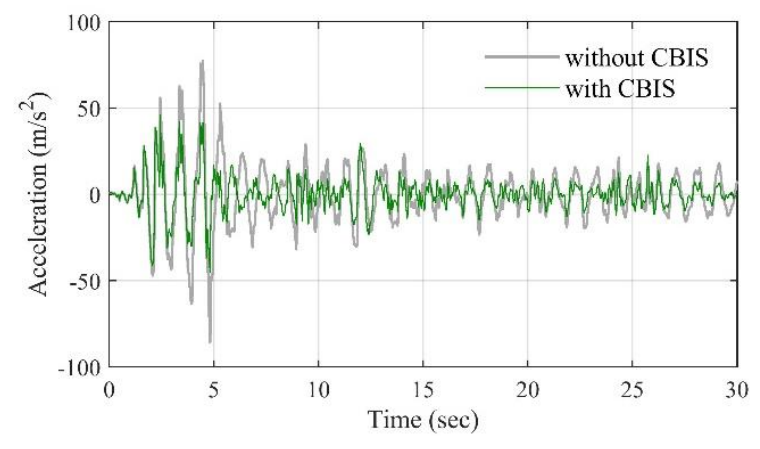

(a)

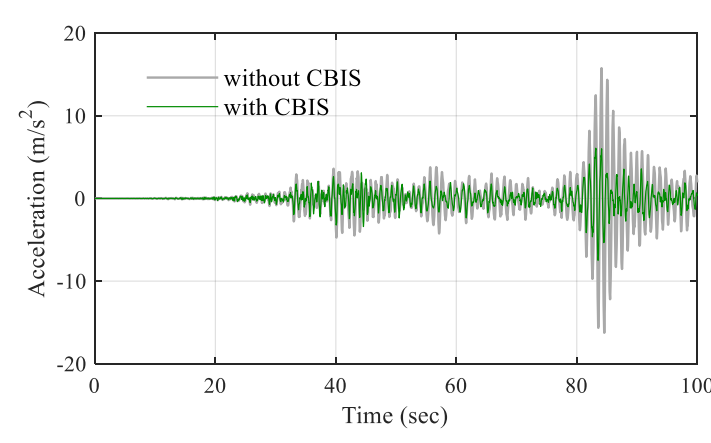

(b)

Figure 10. Cont. 


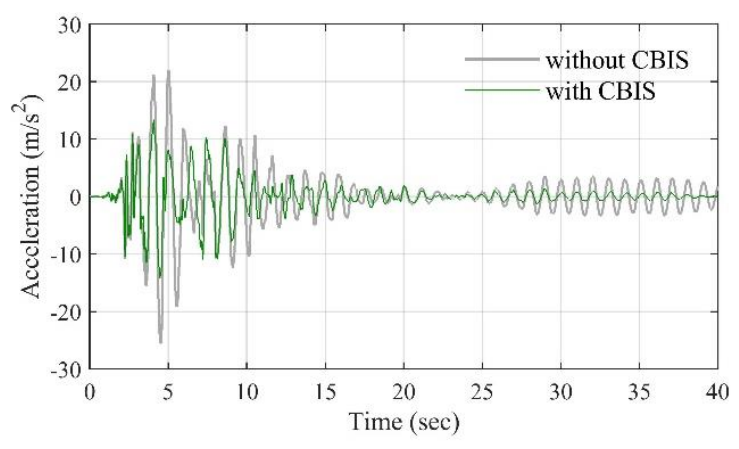

(c)

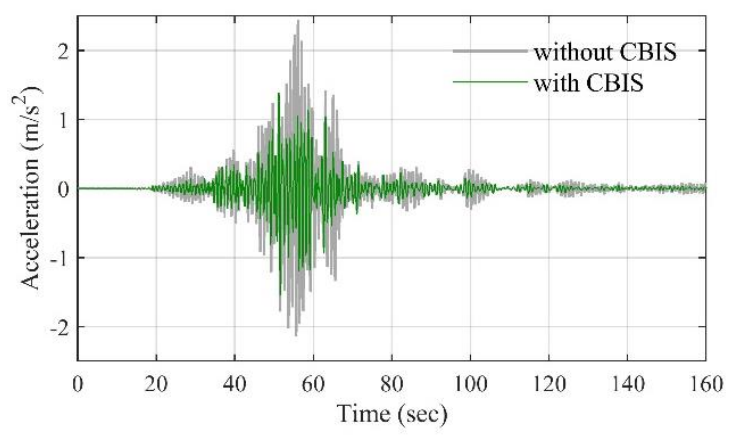

(d)

Figure 10. Acceleration response time histories for two test frame roofs during (a) the El Centro wave, (b) the Tohoku wave recorded by Tohoku University, (c) the Kobe record and (d) the Chi-chi record.

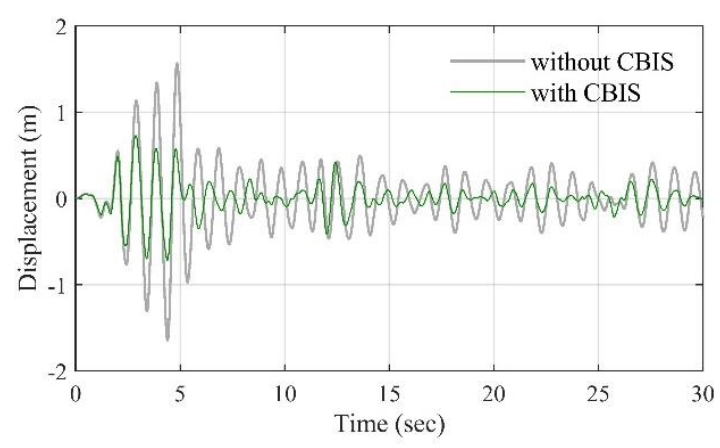

(a)

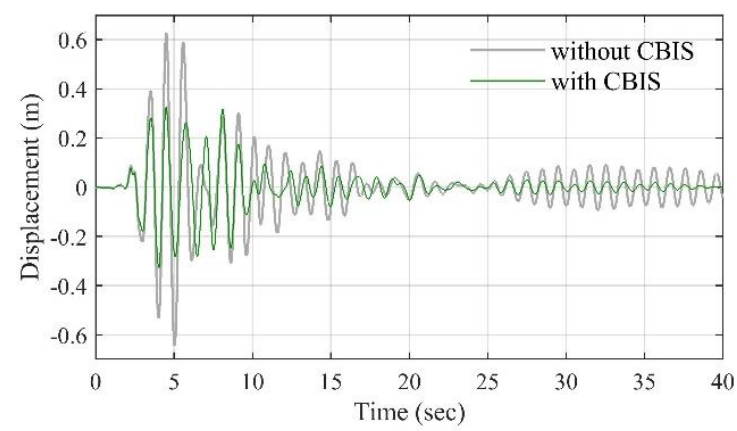

(c)

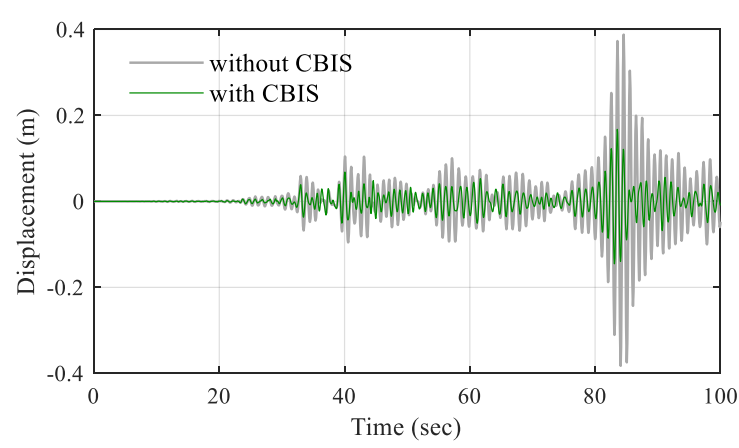

(b)

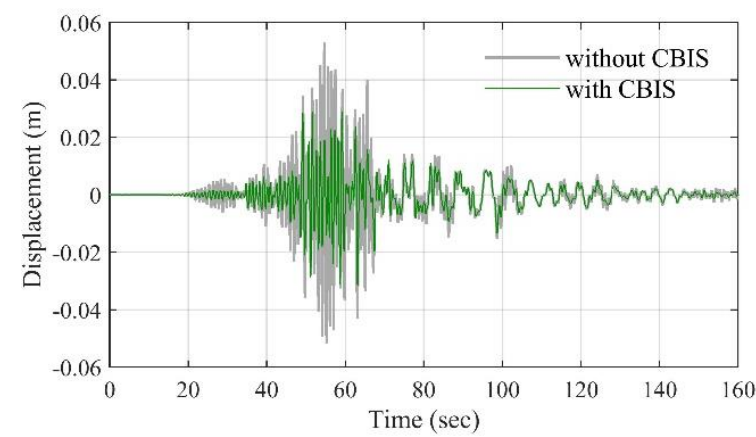

(d)

Figure 11. Displacement response time histories for two test frame roofs during (a) the El Centro wave, (b) the Tohoku wave recorded by Tohoku University, (c) the Kobe record and (d) the Chi-chi record.

The vibration reduction effect is defined as:

$$
\text { Reduction effect }=\frac{\text { Response of uncontrolled structure-Response of controlled structure }}{\text { Response of uncontrolled structure }} \times 100 \% \text {. }
$$

The results are listed in Tables 2 and 3. The reduction effects were favorable under the El Centro wave, Tohoku wave, Kobe record and $\mathrm{Chi}$-chi record. The best vibration control effects for the peak and RMS values of the acceleration responses were $52.08 \%$ and $45.71 \%$ (marked in bold), respectively. The values for the displacement responses were $55.56 \%$ and $52.50 \%$, respectively. 
Table 2. Acceleration responses at the roof of the test frame $\left(\mathrm{m} / \mathrm{s}^{2}\right)$.

\begin{tabular}{c|c|c|c|c|c|c|c|c}
\hline \multirow{2}{*}{ Seismic Input } & \multicolumn{2}{|c|}{ El Centro Record } & \multicolumn{2}{c|}{$\begin{array}{c}\text { The Tohoku } \\
\text { University Record }\end{array}$} & \multicolumn{2}{c|}{ Kobe Record } & \multicolumn{2}{c}{ Chi-Chi Record } \\
\cline { 2 - 10 } & Peak & RMS & Peak & RMS & Peak & RMS & Peak & RMS \\
\hline Uncontrolled & 8.77 & 1.74 & 16.59 & 1.85 & 25.47 & 4.75 & 2.44 & 0.35 \\
\hline Controlled & 4.75 & 1.04 & 7.95 & 1.16 & 14.14 & 2.91 & 1.55 & 0.19 \\
\hline Reduction effects (\%) & 45.84 & 40.23 & $\mathbf{5 2 . 0 8}$ & 37.30 & 44.48 & 38.74 & 36.48 & $\mathbf{4 5 . 7 1}$ \\
\hline
\end{tabular}

Table 3. Displacement responses at the roof of the test frame (m).

\begin{tabular}{c|c|c|c|c|c|c|c|c}
\hline \multirow{2}{*}{ Seismic Input } & \multicolumn{2}{|c|}{ El Centro Record } & \multicolumn{2}{c|}{$\begin{array}{c}\text { The Tohoku } \\
\text { University Record }\end{array}$} & \multicolumn{2}{c|}{ Kobe Record } & \multicolumn{2}{c}{ Chi-Chi Record } \\
\cline { 2 - 9 } & Peak & RMS & Peak & RMS & Peak & RMS & Peak & RMS \\
\hline Uncontrolled & 0.168 & 0.040 & 0.396 & 0.046 & 0.646 & 0.129 & 0.053 & 0.009 \\
\hline Controlled & 0.077 & 0.019 & 0.176 & 0.026 & 0.327 & 0.081 & 0.032 & 0.005 \\
\hline Reduction effects (\%) & 54.17 & $\mathbf{5 2 . 5 0}$ & $\mathbf{5 5 . 5 6}$ & 43.48 & 49.38 & 37.21 & 39.62 & 44.44 \\
\hline
\end{tabular}

\subsection{Ignoring the Flexibility of the Cable}

To simplify the CBIS analytical model, the flexibility of the cable is neglected as shown in Figure 12.

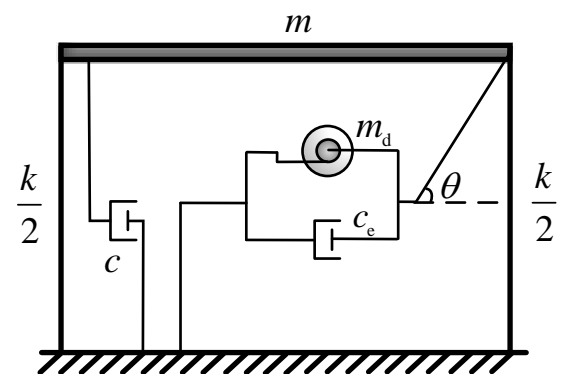

Figure 12. Simplified analytical model of the CBIS-equipped SDOF structure.

Consider this simplified CBIS-equipped SDOF structure as a model with no connection element flexibility. The relationship between the axial deformation of the cable and the rotational angle of the shaft is expressed as:

$$
\varphi(t)=\frac{u(t) \cos \theta}{r_{0}} .
$$

The equation of motion for an SDOF model with a CBIS is given by:

$$
\left(m+\frac{J \cos ^{2} \theta}{r_{0}^{2}}\right) \ddot{u}(t)+\left(c_{0}+c_{\mathrm{d}} \cos ^{2} \theta\right) \dot{u}(t)+k u(t)=-m a_{\mathrm{g}}(t) .
$$

In Equation (33), $\frac{J \cos ^{2} \theta}{r_{0}{ }^{2}}$ is $m_{\mathrm{d}}$, which is namely the inertance of the inerter. From Equation (33), it can be understood that the utilization of CBIS induces the elongation of the natural period and increases the damping effect. The mass of the primary structure is affected, while the stiffness of the overall structure remains unaffected. By using the Laplace transformations, the transfer function can be easily obtained as:

$$
H_{U}(s)=\frac{U(s)}{A_{\mathrm{g}}(s)}=\frac{-1}{(1+\mu) s^{2}+\left(2 \zeta \omega_{\mathrm{s}}+2 \xi \omega_{\mathrm{s}} \cos ^{2} \theta\right) s+\omega_{\mathrm{s}}^{2}} .
$$

We assume a single-floor frame structure, which can usually be treated as an SDOF structure. The key parameters of the structure and the inerter system are as follows: inherent damping ratio is $\zeta$ $=0.02$, the tilt angle of the cable is $\theta=\pi / 4$, the inertance-mass ratio is $\mu=0.1,0.2$, and the damping 
ratio is $\xi=0.01,0.05,0.1$. By using these parameters, the displacement amplification factor can be plotted as shown in Figure 13.

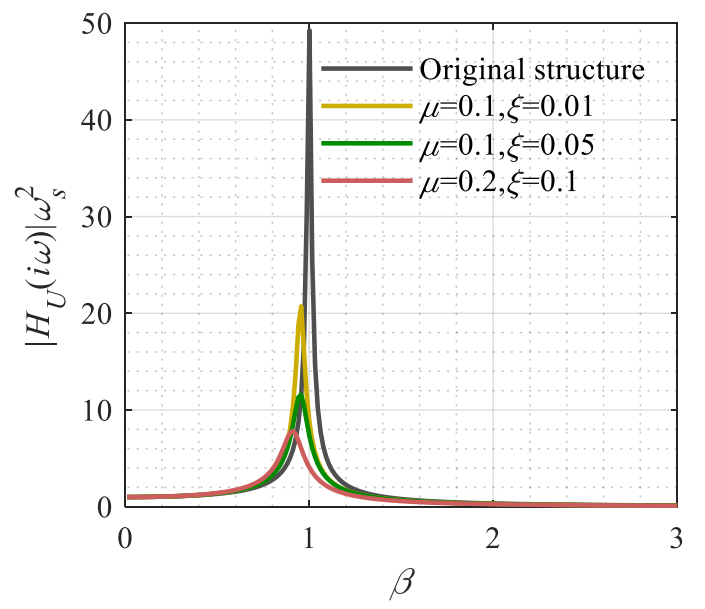

Figure 13. Displacement amplification factors of the SDOF structure with different inerter systems.

Figure 13 shows that inerter systems can significantly suppress the resonant response in a narrow band near the natural frequency of the primary structure but does not impact the other range of frequencies.

\section{Conclusions}

A novel inerter system for vibration control, which uses tension-only cables for translation-to-rotation conversion, was proposed in this paper. This device can be put into practical use with an inertia mass amplification element, enabling it to simultaneously achieve the displacement amplification effect. To study the performance of a CBIS on the seismic response mitigation of structures, the motion equations, both with and without flexibility of the cable, were derived and studied based on parametric analysis.

CBIS has the potential for seismic rapid retrofit of structures due to their easy installation and adaptive deployment. In this system, cables are used to convert translational deformation of the primary structure into the rotational motion of the fly wheels; thus, small actual mass can be amplified to large inertance by several hundred times. The proposed cable-bracing system can be adjusted for various frame configurations and design capacities. It can be installed in any direction and part of the structure as long as there exists relative deformation, not limited to horizontal vibration. This cable-bracing system uses simple connections with rapid and adjustable installation. It has the advantages of lower construction cost and easy replacement. The CBIS with a non-contacting damping mechanism shows excellent performance in the adjustable damping ratio by varying the air gap between the permanent magnet and the conductor.

The CBIS is an effective structural response mitigation device used to mitigate the response of structural systems under dynamic excitation. The peak and RMS responses of the SDOF structure were reduced after they were equipped with this system. To obtain a more rational parameter set for practical design, the demand-oriented multi-objective optimum design method is used to find the boundary of the feasible criterion space. Using the proposed method, the parameters of the CBIS can be effectively designed to satisfy the target vibration mitigation effects.

The vibration mitigation effect of an SDOF structure with the inerter system was analyzed in this paper. Future research will explore its application to multi-degree of freedom structures. Currently, a physical realization of the CBIS has been developed, and experimental verifications, including free vibration and shaking table tests, are underway. 
Author Contributions: Conceptualization, L.X. and S.X.; methodology, X.B.; software, X.B., J.K.; validation, K.I.; formal analysis, L.X. and X.B.; data curation, J.K. and S.X.; writing-original draft preparation, X.B.; writing-review and editing, H.T.

Funding: This study was supported by the National Natural Science Foundation of China (Grant No. 51478356, No. 51778490), the Key Program for International S\&T Cooperation Projects of China (Grant No. 2016YFE0127600), Open Research Fund Program of Guangdong Key Laboratory of Earthquake Engineering and Application Technology (Grant No. 2017B030314068), the Ministry of Science and Technology of China (Grant No. SLDRCE19-B-02), and the National Key R\&D Program of China (Grant No. 2017YFC0703607).

Conflicts of Interest: The authors declare no conflict of interest.

\section{References}

1. Housner, G.W.; Bergman, L.A.; Caughey, T.K.; Chassiakos, A.G.; Claus, R.O.; Masri, S.F.; Skelton, R.E.; Soong, T.T.; Spencer, B.F.; Yao, J.T.P. Structural control: Past, present, and future. J. Eng. Mech 1997, 123, 897-971. [CrossRef]

2. Yao, J.T.P. Concept of structural control. J. Struct. Div. 1972, 98, 1567-1574.

3. Mahmoodi, P. Structural dampers. J. Struct. Div. 1969, 95, 1661-1672.

4. Frahm, H. Device for Damping Vibrations of Bodies. U.S. Patent 989,958, 18 April 1911.

5. Miyamoto, H.K.; Gilani, A.S.J.; Garza, J.; Stephen, A.M. Seismic Retrofit of a Landmark Structure Using a Mass Damper. In Proceedings of the Conference on Improving the Seismic Performance of Existing Buildings and Other Structures, San Francisco, CA, USA, 9-11 December 2009.

6. Tributsch, A.; Adam, C. Evaluation and analytical approximation of Tuned Mass Damper performance in an earthquake environment. Smart Struct. Syst. 2012, 10, 155-179. [CrossRef]

7. Sadek, F.; Mohraz, B.; Taylor, A.W.; Chung, R.M. A method of estimating the parameters of tuned mass dampers for seismic applications. Earthq. Eng. Struct. Dyn. 1997, 26, 617-635. [CrossRef]

8. Cao, H.; Reinhorn, A.M.; Soong, T.T. Design of an active mass damper for a tall TV tower in Nanjing, China. Eng. Struct. 1998, 20, 134-143. [CrossRef]

9. Ikago, K.; Saito, K.; Inoue, N. Seismic control of single-degree-of-freedom structure using tuned viscous mass damper. Earthq. Eng. Struct. Dyn. 2012, 41, 453-474. [CrossRef]

10. Ikago, K.; Sugimura, Y.; Saito, K.; Inoue, N. Simple Design Method for a Tuned Viscous Mass Damper Seismic Control System. In Proceedings of the 15th World Conference on Earthquake Engineering, Lisbon, Portugal, 24-28 September 2012.

11. Lazar, I.F.; Neild, S.A.; Wagg, D.J. Vibration suppression of cables using tuned inerter dampers. Eng. Struct. 2016, 122, 62-71. [CrossRef]

12. Marian, L.; Giaralis, A. Optimal design of a novel tuned mass-damper-Inerter (TMDI) passive vibration control configuration for stochastically support-excited structural systems. Probab. Eng. Mech. 2014, 38, 156-164. [CrossRef]

13. Saito, K.; Inoue, N. A study on optimum response control of passive control systems using viscous damper with inertial mass: Substituting equivalent nonlinear viscous elements for linear viscous elements in optimum control systems. AIJ J. Technol. Des. 2007, 13, 457-462. [CrossRef]

14. Saito, K.; Toyota, K.; Nagae, K.; Sugimura, Y.; Nakano, T.; Nakaminam, I.S.; Arima, F. Dynamic loading test and application to a high-rise building of viscous damping devices with amplification system. In Proceedings of the Third World Conference on Structural Control, Como, Italy, 11 April 2002.

15. Zhang, R.; Zhao, Z.; Dai, K. Seismic response mitigation of a wind turbine tower using a tuned parallel inerter mass system. Eng. Struct. 2019, 180, 29-39. [CrossRef]

16. Zhao, Z.; Zhang, R.; Lu, Z. A particle inerter system for structural seismic response mitigation. J. Frankl. Inst. 2019, 193, 110-120. [CrossRef]

17. Smith, M.C. Synthesis of mechanical networks: The inerter. IEEE Trans. Automat. Control 2002, 47, 1648-1662. [CrossRef]

18. Saito, K.; Sugimura, Y.; Nakaminami, S.; Kida, H.; Inoue, N. Vibration Tests of 1-Story Response Control System Using Inertial Mass and Optimized Softy Spring and Viscous Element. In Proceedings of the 14th World Conference on Earthquake Engineering, Beijing, China, 12-17 October 2008.

19. Chen, M.Z.; Hu, Y.; Huang, L.; Chen, G. Influence of inerter on natural frequencies of vibration systems. J. Sound Vib. 2014, 333, 1874-1887. [CrossRef] 
20. Arakaki, T.; Kuroda, H.; Arima, F.; Inoue, Y.; Baba, K. Development of seismic devices applied to ball screw. Part 1: Basic performance test of RD-series. AIJ J. Technol. Des. 1999, 5, 239-244. [CrossRef]

21. Ikago, K.; Sugimura, Y.; Saito, K.; Inoue, N. Modal response characteristics of a multiple-degree-of-freedom structure incorporated with tuned viscous mass dampers. J. Asian Architect. Build. Eng. 2012, 11, 375-382. [CrossRef]

22. Lazar, I.F.; Neild, S.A.; Wagg, D.J. Using an inerter-based device for structural vibration suppression. Earthq. Eng. Struct. Dyn. 2014, 43, 1129-1147. [CrossRef]

23. Makris, N.; Kampas, G. Seismic protection of structures with supplemental rotational inertia. J. Eng. Mech. 2016, 142, 1-11. [CrossRef]

24. Papageorgiou, C.; Houghton, N.E.; Smith, M.C. Experimental testing and analysis of inerter devices. J. Dyn. Syst. Meas. Control 2009, 131, 101-116. [CrossRef]

25. Nakamura, Y.; Fukukita, A.; Tamura, K.; Yamazaki, I.; Matsuoka, T.; Hiramoto, K.; Sunakoda, K. Seismic response control using electromagnetic inertial mass dampers. Earthq. Eng. Struct. Dyn. 2014, 43, 507-527. [CrossRef]

26. Wang, F.C.; Hong, M.F.; Lin, T.C. Designing and testing a hydraulic inerter. Proc. Inst. Mech. Eng. Part C J. Mech. Eng. Sci. 2011, 225, 66-72. [CrossRef]

27. Kawamata, S. Liquid type mass damper with elongated discharge tube. U.S. Patent 4,872,649, 10 October 1989.

28. Smith, M.C.; Houghton, N.E.; Long, P.J.G.; Glover, A.R. Force-Controlling Hydraulic Device. U.S. Patent 8,881,876, 11 November 2014.

29. Høgsberg, J.; Brodersen, M.L.; Krenk, S. Resonant passive-active vibration absorber with integrated force feedback control. Smart Mater. Struct. 2016, 25, 047001. [CrossRef]

30. Wang, F.C.; Chen, Y.C.; Lee, C.H. Design and Optimization of Inerter Layouts for a Multi-Layers Building Model. In Proceedings of the 55th Annual Conference of the Society of Instrument and Control Engineers of Japan, IEEE, Tsukuba, Japan, 20-23 September 2016.

31. Sugimura, Y.; Goto, W.; Tanizawa, H.; Saito, K.; Ninomiya, T. Response Control Effect of Steel Building Structure Using Tuned Viscous Mass Damper. In Proceedings of the 15th World Conference on Earthquake Engineering, Lisbon, Portugal, 24-28 September 2012.

32. Pan, C.; Zhang, R.; Luo, H.; Li, C.; Shen, H. Demand-based optimal design of oscillator with parallel-layout viscous inerter damper. Struct. Control Health Monit. 2017, 25, e2051. [CrossRef]

33. Pan, C.; Zhang, R. Design of structure with inerter system based on stochastic response mitigation ratio. Struct. Control Health Monit. 2018, 25, e2169. [CrossRef]

34. Zhang, R.; Zhao, Z.; Pan, C. Influence of mechanical layout of inerter systems on seismic mitigation of storage tanks. Soil Dyn. Earthq. Eng. 2018, 114, 639-649. [CrossRef]

35. Chen, Q.; Zhao, Z.; Zhang, R.; Pan, C. Impact of soil-structure interaction on structures with inerter system. J. Sound Vib. 2018, 433, 1-15. [CrossRef]

36. Hwang, J.S.; Kim, J.; Kim, Y.M. Rotational inertia dampers with toggle bracing for vibration control of a building structure. Eng. Struct. 2007, 29, 1201-1208. [CrossRef]

37. Tan, S.; Astaneh-Asl, A. Use of steel cables to prevent progressive collapse of existing buildings. In Proceedings of the sixth conference on tall buildings in seismic regions, Los Angeles, CA, USA, 4 June 2003.

38. Kim, J.; Choi, H.; Min, K.W. Use of rotational friction dampers to enhance seismic and progressive collapse resisting capacity of structures. Struct. Des. Tall Spec. Build. 2011, 20, 515-537. [CrossRef]

39. Kurata, M.; Leon, R.T.; Desroches, R. Rapid seismic rehabilitation strategy: Concept and testing of cable bracing with couples resisting damper. J. Struct. Eng. 2012, 138, 354-362. [CrossRef]

(C) 2019 by the authors. Licensee MDPI, Basel, Switzerland. This article is an open access article distributed under the terms and conditions of the Creative Commons Attribution (CC BY) license (http://creativecommons.org/licenses/by/4.0/). 